ARTIGO

Recebido em: 08/05/2017

Aceito em: 10/11/2017

\title{
Indícios da inteligência coletiva no regime de informação do Laboratório de Tecnologias Intelectuais - LT $i$
}

\author{
Evidence of collective intelligence in information regime \\ of Intellectuals Technologies Laboratory - LTi
}

Isa Maria FREIRE (isafreire@globo.com)*

* Professora do Departamento de Ciência da Informação- UFPB.

Resumo: Apresenta resultado de reflexão sobre as ações de informação em curso no regime de informação do Projeto Laboratório de Tecnologias Intelectuais - LTi, considerando a possibilidade da emergência de uma inteligência coletiva na comunidade acadêmica. 0 padrão que une a trama do texto é a possibilidade de inclusão na sociedade em rede mediante ações de informação para apropriação, produção e compartilhamento cooperativo de tecnologias intelectuais de informação e comunicação. Discorre sobre os domínios, estratos e modalidades das ações de informação no regime de informação, analisando suas características e cotejando com as ações de informação em desenvolvimento no Projeto LTi. Finaliza identificando indícios de que os fios reunidos na rede conceitual do Projeto LTi, destacando-se os construtos responsabilidade social, regime de informação e inteligência coletiva, se entrelaçam no tear interdisciplinar da Ciência da Informação e nas ações de informação em curso no regime de informação do Projeto LTi .

Palavras-chave: Rede conceitual. Regime de informação. Inteligência coletiva. Método indiciário. Laboratório de Tecnologias Intelectuais - LTi

\begin{abstract}
It presents the result of reflection exercise on information current actions in the information regime of Intellectual Technologies Laboratory Project - LTi, considering the emergence of a collective intelligence in the academic community. The pattern that unites the text frame is the possibility of inclusion in the network society through information actions to ownership, production and cooperative sharing of intellectual information and communication technologies. Discusses areas, strata and types of information actions in the information regime, analyzing their characteristics and comparing with the information actions in development in LTi Project. Terminates identifying evidence that the wires assembled in the conceptual network of LTi Project, such as social responsibility constructs, information regime and collective intelligence intertwine in interdisciplinary loom of Information Science and ongoing information actions in the information regime of the LT $\boldsymbol{i}$ Project.
\end{abstract}

Keywords: Conceptual network. Information regime. Collective intelligence. Evidential method. Intellectuals Technologies Laboratory - LTi.

v. 23 , n. 51,2018 p. $44-58$

ISSN 1518-2924

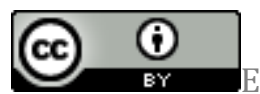




\section{INTRODUÇÃO}

No presente relato de pesquisa compartilhamoso resultado de exercício de reflexão sobre as ações de informação em curso no regime de informação do Projeto Laboratório de Tecnologias Intelectuais - LTi, ${ }^{1}$ considerando a possibilidade de emergência de uma inteligência coletiva em uma comunidade acadêmica. ${ }^{2}$

Nosso propósito é seguir o fio de reflexões já realizadas em exercícios anteriores, ${ }^{3}$ a partir da premissa de uma responsabilidade social da Ciência da Informação na sociedade contemporânea, de modo a tecer uma rede onde se entrelacem os conceitos de sociedade em rede, inteligência coletiva e regime de informação, no contexto da rede de projetos ${ }^{4} \mathrm{em}$ desenvolvimento no Projeto LTi. 0 padrão que une a trama da rede, no tear interdisciplinar da Ciência da Informação, é a possibilidade de promover ações de informação colaborativas para apropriação, produção e compartilhamento de tecnologias intelectuais de informação e comunicação.

No presente exercício, buscamos identificar os indícios de um projeto de inteligência coletiva no desenvolvimento de ações de informação no regime de informação do Projeto LTi. com ênfase nas ações formativas, características de uma forma de vida, aqui definida como a forma de vida da comunidade acadêmica da área de Ciência da Informação da Universidade Federal da Paraíba.

Ao compartilhar este relato, esperamos contribuir para a discussão do modelo de rede conceitual de Wersig (1993) como abordagem própria e apropriada aos problemas de informação, em um dado regime de informação, na sociedade contemporânea.

\section{CONTEXTO}

Como urdidura para os fios do nosso texto, apresentamos, a seguir, o modelo de rede conceitual a partir da qual fundamentamos nossas ações de informação no espaço do LTi, na perspectiva da Ciência da Informação.

Em 1993, Wersig sugeriu para a ciência da informação uma estrutura teórica que considerasse menos a formulação de leis gerais e mais a de estratégias de ação, mediante uma abordagem de entrelaçamento de conceitos científicos da área da Ciência da Informação e áreas correlacionadas. Para o autor, essa estrutura seria entretecida como uma rede conceitual, a partir da qual abordagens teóricas e metodológicas poderiam entrelaçar seus fios conceituais numa "rede conceitual" na Ciência da Informação.

A abordagem da rede conceitual foi aplicada por Freire (2001) para demonstrar a responsabilidade social como fundamento da Ciência da Informação na sociedade contemporânea - premissa a partir da qual será tecida a presente rede conceitual, em cuja trama também se destacam os construtos regime de informação e inteligência coletiva.

A partir desse modelo destacamos, na presente comunicação, o entrelaçamento dos estratos e modalidades das ações de informação em curso no regime de informação do LTi, que oferecem aos participantes da rede de projetos oportunidades para apreender as competências necessárias para apropriação, produção e compartilhamento de informações científicas e tecnológicas na internet.

\footnotetext{
${ }^{1}$ Com apoio do CNPq - Edital Universal 2009, 2011, 2014.

2 Foi apresentada comunicação oral no XVII ENANCIB. 0 presente artigo incorpora a inestimável contribuição da discussão com a comunidade de pesquisadores, tanto no texto quanto na representação (figuras).

${ }^{3}$ Freire, 2012; 2013; 2014; 2015.

${ }^{4}$ Metodologia operacional desenvolvida por Freire (2004) e aplicada no Projeto LTi.
} 
Na figura 1, a seguir, representamos a rede conceitual em que se fundamenta nossa abordagem no Projeto LTi:

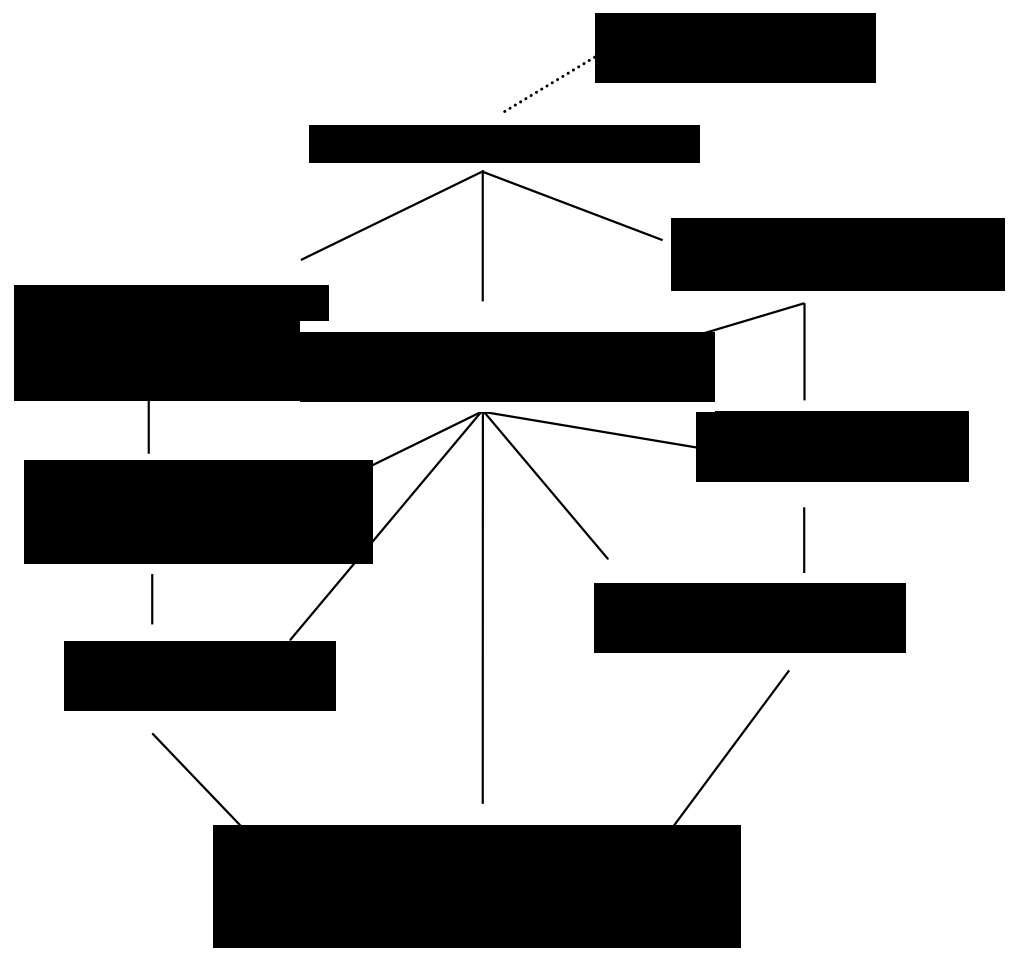

Figura 1: Rede conceitual do Projeto LTi

Fonte: Freire, 2014.

Nessa abordagem, destacamos a comunidade científica como espaço de criação e compartilhamento da informação e do conhecimento, e a Ciência da Informação como tear interdisciplinar onde se reúnem os fios da trama no contexto de um problema de informação. Pois, atualmente estamos presenciando a nova relevância de um fenômeno antigo - a informação - cuja área de ação e atuação cresceu de tal forma, ao longo do século XX, que veio a se identificar com a própria sociedade, também qualificada, entre outros, como sociedade da informação.

Com a proposta do LTi, esperamos criar novas possibilidades de aprendizagem entre os participantes - pesquisadores docentes e discentes - para produção cooperativa e compartilhamento de informações de interesse para a comunidade acadêmica ${ }^{5}$ da área de Ciência da Informação na Universidade Federal da Paraíba. Como não poderia deixar de ser, a trama da nossa rede conceitual é tecida no espaço social da contemporaneidade, que se realiza no mundo da vida das sociedades humanas, na forma da vida acadêmica e no mundo virtual das comunidades constituídas no ciberespaço ${ }^{6}$.

50 termo comunidade acadêmica foi adotado por sua abrangência em relação às singularidades na forma de vida dos atores no regime de informação do LTi $\boldsymbol{i}$, cuja equipe inclui pesquisadores-docentes da pós-graduação, docentes da graduação, discentes da pósgraduação e da graduação, e profissionais interessados no processo de produção e compartilhamento da informação na internet.

${ }^{6}$ Para Lévy (1999, p.36, grifo do autor), "o ciberespaço [também chamado de rede] é o novo meio de comunicação que surge da interconexão mundial dos computadores, mediante a Internet. 0 termo especifica não apenas a infraestrutura material da comunicação digital, mas também o universo oceânico de informações que ela abriga, assim como os seres humanos que navegam e alimentam esse universo". 


\subsection{A inteligência coletiva no espaço do saber}

Conforme Lévy (2000, p.11), desde os anos 1970 o curso dos acontecimentos mundiais vem convergindo "para a constituição de um novo meio de comunicação, de pensamento e de trabalho para as sociedades humanas, o ciberespaço", o qual emerge a partir da interconexão mundial dos computadores mediada pela Internet. Para o autor, o termo especifica tanto a infraestrutura material da comunicação digital como, também, o universo de informações em fluxo no sistema e as que navegam e interagem nesse espaço virtual. Nas palavras de Wertheim (2001, p.32), "Esse espaço formou-se, a partir do nada, em pouco mais de um quarto de século, o que faz dele o 'território' de mais rápido crescimento da história”. Nessa perspectiva, podemos estar vivendo um desses momentos especiais, "em que uma civilização inventa a si própria, deliberadamente", de modo que em pouco tempo podemos vir a passar "de uma humanidade a outra" (LÉVY, 2000, p.60), como ocorreu, por exemplo, depois da invenção da escrita, na Mesopotâmia, e da multiplicação da prensa gráfica de Gutenberg, na Europa medieval, entre outros eventos paradigmáticos.

Pois ao longo do tempo histórico as sociedades humanas desenvolveram espaços antropológicos, que se iniciam com a possibilidade de exploração do primeiro grande espaço aberto à nossa espécie: a Terra. Os modos de conhecimento específicos desse primeiro espaço são os mitos e os ritos. O segundo espaço antropológico, do Território, teria emergido com o neolítico e suas inovações socioculturais: a agricultura, a cidade, o estado e a escrita. Aqui, "começa a história e o desenvolvimento dos saberes de tipo sistemático, teórico ou hermenêutico" (LÉVY, 2000, p.24), e surgem as organizações orientadas por lógicas de pertencimento ou de exclusão. 0 terceiro espaço, das Mercadorias, tem o fluxo como princípio organizador: fluxo de energias, de matérias-primas, mercadorias, capitais, mão-deobra, informações. Este espaço não elimina os anteriores, contudo,

[...] supera-os em velocidade. É o novo motor da evolução. A riqueza não provém do domínio das fronteiras, mas do controle dos fluxos. Daí por diante reina a indústria, no sentido amplo de tratamento da matéria e da informação. A ciência experimental moderna é um modo de conhecimento típico do novo espaço [...] (LÉVY, 2000, p.24)

Do espaço de fluxos de mercadorias emerge o espaço caracterizado pela inteligência e pelo saber coletivos, o qual teria uma função hegemônica os demais espaços antropológicos, rumo a um estágio que Lévy (2000, p.24) denomina "noolítico"7. Na figura 2, a seguir, apresentamos uma representação da emergência e crescimento da inteligência coletiva, no tempo histórico, desde o espaço das mercadorias até o espaço do saber contemporâneo:

7 "Idade da pedra do espírito. A pedra não é mais aqui o sílex, mas o silício dos microprocessadores e da fibra ótica" (LÉVY, 2000, p.24). 


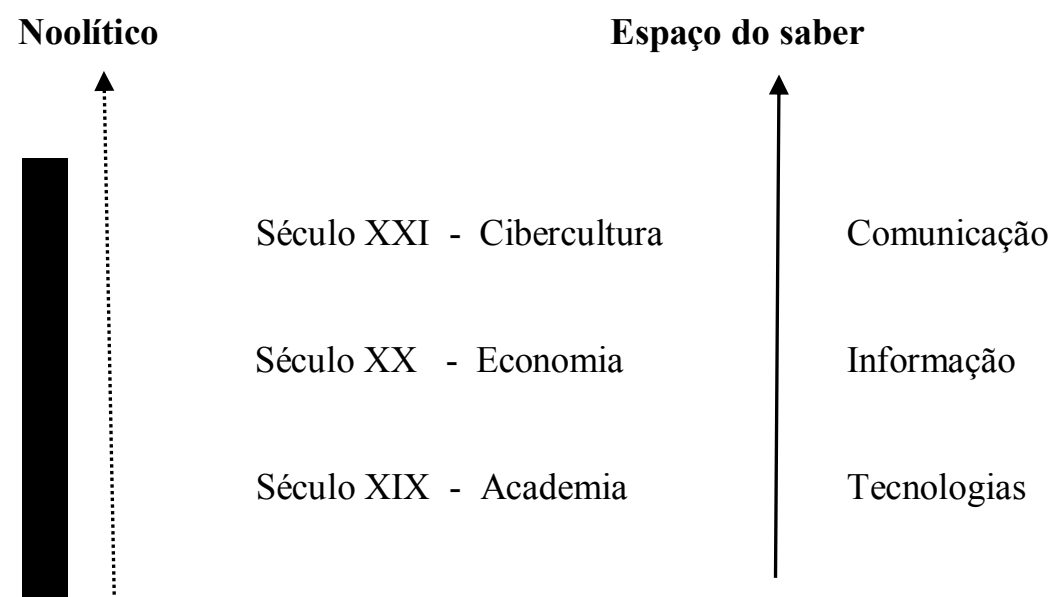

Espaço das mercadorias

Figura 2: Do espaço das mercadorias ao espaço do saber Fonte: FREIRE, 2016 a partir de Lévy (2000).

A partir de suas observações sobre o "extraordinário fenómeno de transformação social contemporâneo", Levy formula as seguintes premissas:

1. a inteligência coletiva, isto é, o processo social de intercâmbio e de produção dos conhecimentos, torna-se uma espécie de economia de mercado ampliada, que vem se constituindo, progressivamente, como inteligência coletiva;

2. o ciberespaço, que se articula com a convergência progressiva de um mercado "que se liberta e se virtualiza, [e com] o processo de inteligência coletiva e de crescimento dinâmico do saber que caracteriza a espécie humana" (LÉVY, 2001, p.61-65).

$\mathrm{O}$ autor argumenta que a primeira comunidade que se organizou como inteligência coletiva, independentemente de barreiras, foi a comunidade científica, o que se explica por sua finalidade própria de atuar como inteligência coletiva.

Ao oferecer a Internet ao mundo, [a comunidade científica] deulhe a infra-estrutura técnica de uma inteligência colectiva que é, sem dúvida, a sua mais bela descoberta. Assim, transmitiu ao resto da humanidade a sua melhor invenção, a do seu próprio modo de sociabilidade, do seu tipo humano e da sua comunicação. Esta inteligência colectiva aperfeiçoada desde há séculos é perfeitamente encarnada pelo caráter livre, sem fronteiras, interconectado, cooperativo e competitivo da web e das comunidades virtuais. (LÈVY, 2001, p.87)

Lévy (2001) argumenta que a primeira comunidade que se organizou como inteligência coletiva, independentemente de barreiras, foi a comunidade científica, o que se explica por sua finalidade própria de atuar como inteligência coletiva. E,

Ao oferecer a Internet ao mundo, [a comunidade científica] deulhe a infra-estrutura técnica de uma inteligência colectiva que é, sem dúvida, a sua mais bela descoberta. Assim, transmitiu ao resto da humanidade a sua melhor invenção, a do seu próprio modo de sociabilidade, do seu tipo humano e da sua comunicação. [...]. (LÈVY, 2001, p.87)

Nesse contexto, a comunidade científica foi a primeira que se organizou como inteligência coletiva, independentemente de barreiras políticas ou culturais. 
[...] A partir do século XVI, a comunidade científica dedicou-se a inventar e a viver uma maneira de fazer sociedade distante tanto da fusão comunitária ou da submissão a uma autoridade despótica como do individualismo indiferente aos outros. [...] No espaço intelectual aberto pela comunidade científica, todas as ideias estão em competição cooperativa para atrair o máximo de atenção. A capacidade de interessar sem recorrer a argumentos de autoridade, à força ou a meios desleais são essenciais ao funcionamento do meio científico porque a finalidade própria deste meio é funcionar como inteligência colectiva. [...] é por isso que a originalidade e a imaginação, a honestidade e a abertura de espírito são virtudes capitais do cientista. (LÉVY, 2001, p.85. Mantida a grafia e itálicos do original)

Nesse processo histórico de constituição do espaço do saber, especialmente desde o advento da economia da informação, o mercado apoderou-se das infraestruturas de comunicação e do modo de funcionamento da comunidade científica, pois também tem como objetivo a inteligência coletiva:

[...] Tanto a iniciativa científica como a empresa capitalista estão envolvidos numa espécie de corrida à melhor cooperação, e é precisamente isto que constitui o seu extraordinário sucesso histórico. [...]

O Homo academicus e o Homo economicus fundem-se no momento em que o mercado se torna um lugar sem fronteiras de circulação das notícias, de intercâmbio de informações e de competição de ideias. [...] 0 principal motor desta transformação é a entrada em concorrência planetária das universidades provocada pela facilidade dos transportes e, sobretudo, pelo desenvolvimento do ciberespaço [...]

[...] Os estudantes são simultaneamente a matéria-prima a transformar e os clientes das universidades. [...] A competição, isto é, a multiplicação das formas, é a dimensão de liberdade da inteligência colectiva. (LÉVY, 2001, p.88-114 passim. Itálico no original)

No contexto do espaço do saber as tecnologias digitais de informação e comunicação devem nos permitir "compartilhar nossos conhecimentos e apontá-los uns para os outros, o que é a condição elementar da inteligência coletiva" (LÉVY, 2000, p.18), de modo a engajar a própria identidade pessoal na atividade profissional, numa dupla mobilização: individual, mas coletiva, ética e cooperativa.

Nesse processo social de construção da inteligência coletiva, destaca-se a relevância do desenvolvimento de uma "engenharia do laço social", a qual pode ser vista como "a arte de suscitar coletivos inteligentes e valorizar ao máximo a diversidade das qualidades humanas" (LÉVY, 2000, p.32). No núcleo dessa engenharia do laço social, se desenvolve a economia das qualidades humanas, cuja ação implicaria necessariamente na emergência de uma ética da inteligência coletiva, ou uma ética do melhor. Pois na economia noolítica, o capital será o homem total.

Na nossa rede conceitual, destacamos a comunidade acadêmica como espaço de criação e compartilhamento do conhecimento científico, e a Ciência da Informação como tear interdisciplinar onde se reúnem os fios da trama de um contexto, no estudo de um problema de informação. É nessa ambiência que se desenvolvem as ações de informação no regime de informação do Projeto Laboratório de Tecnologias Intelectuais. 


\subsection{0 regime de informação no $L T i$}

Sabemos que regimes de informação existem nas sociedades organizadas desde sempre, ou a partir do momento em que estas sociedades percebem a relevância da informação e passam a desenvolver ações sistemáticas para a sua organização e comunicação, primeiramente para grupos específicos depois para toda a sociedade.

Temos como exemplo arquetípico da presença de regimes de informação na história humana na biblioteca de Alexandria. Essa biblioteca atraía estudiosos da época, inclusive propiciando incentivos materiais àqueles estudiosos que não tinham condições de se manterem na cidade. 0 que poderia ser visto como equivalente às bolsas de incentivo à pesquisa atuais. A relevância da biblioteca também aparece na vigilância dos órgãos da cidade, cujos funcionários revistavam os navios em busca de documentos escritos que pudesses ser interessantes e incorporados ao acervo da biblioteca. 0 que caracteriza a sociedade atual é que 0 regime de informação passa a ser hegemônico.

[Na] nova ordem econômica mundial, que se anuncia nas explanações científicas e na economia das tecnologias digitais, [...] o regime de informação, com seus sistemas de informação e linguagens documentárias, inicia sua hegemonia sobre o regime industrial, na sociedade contemporânea. (UNGER; FREIRE, 2008, p.85)

Nesse contexto, Frohmann (1995) ressalta que, dada a relevância dos regimes de informação na sociedade contemporânea, os estudos visando sua clara representação se apresentam como um "legítimo e premente objetivo na pesquisa em política de informação". Para o autor,

[...] Descrever um regime de informação significa catalogar [mapear] o polêmico processo que resulta da tentativa da inquieta estabilização dos conflitos entre os grupos sociais, interesses, discursos, com os equitativos artefatos científicos e tecnológicos. (FROHMANN, 1995)

Para González de Gómez (2003b, p. 61) o regime de informação vem a ser Um modo de produção informacional dominante numa formação social, conforme o qual serão definidos sujeitos, instituições, regras e autoridades informacionais, os meios e os recursos preferenciais de informação, os padrões de excelência e os arranjos organizacionais de seu processamento seletivo, seus dispositivos de preservação e distribuição.

Nesse quadro de referência, acompanhamos a interpretação de Unger e Freire (2008) quando destacam que é no meio ambiente de trocas materiais (econômicas, tecnológicas, culturais) que ocorrem as relações entre os seres humanos com necessidades informacionais e as fontes de informação e conhecimento relevantes. Os autores acrescentam que regimes são compostos fisicamente por:

- seres humanos, com suas necessidades informacionais - são os atores sociais;

- estudos teóricos, diretrizes políticas e práticas de gestão que direcionam e organizam os conteúdos informacionais abrigados nos sistemas de informação - são os dispositivos;

- estoques de informação, produzidos e disseminados no escopo dos sistemas de comunicação da informação e compartilhados na rede internet - são os artefatos, ou objetos relacionais de informação. (UNGER; FREIRE, 2008, p.87) 
Um regime de informação consiste no conjunto de determinações onde estão definidos os elementos que compõem o fluxo estrutural da produção, organização, comunicação e transferência de informações em um dado espaço social. Em sua pesquisa sobre gestão de informação em um dado regime de informação, Delaia (2008) representou a dinâmica de seus componentes, destacando suas relações recíprocas, como segue:

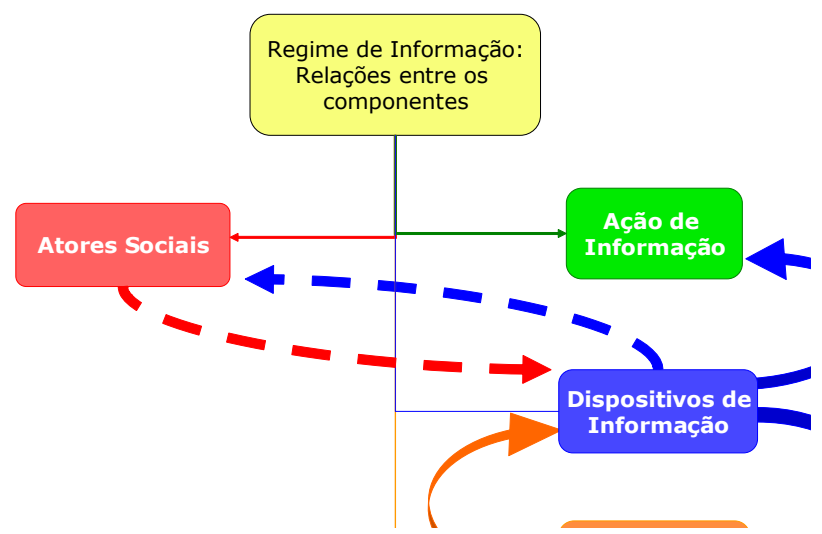

Figura 3: Dinâmica dos elementos em um regime de informação

Fonte: DELAIA, 2008.

Nesse contexto, os dispositivos podem ser considerados um mecanismo operacional, ou um conjunto de meios composto de regras de formação e de transformação desde o seu início, ou como González de Gómez (1999, p.63) "um conjunto de produtos e serviços de informação e das ações de transferência de informação"; os atores são sujeitos sociais que "podem ser reconhecidos por suas formas de vidas e constroem suas identidades através de ações formativas existindo algum grau de institucionalização e estruturação das ações de informação"; e os artefatos de informação, ou objetos relacionais, constituem os modos tecnológicos e materiais de armazenagem, processamento e de transmissão de dados, mensagem, informação (Cf. GONZÁLEZ DE GÓMEZ, 2002, 2003b).

0 regime de informação consiste, pois, no conjunto de determinações onde estão definidos os elementos que compõem o fluxo estrutural da produção, organização, comunicação e transferência de informações em um dado espaço social. Nesse contexto, González de Gómez (2003b, p.61) entende a Ciência da Informação como sendo

[...] aquela que estuda fenômenos, processos, construções, sistemas, redes e artefatos de informação, enquanto 'informação' for definida por ações de informação, as quais remetem aos atores que as agenciam aos contextos e situações em que acontecem e aos regimes de informação em que se inscrevem. (Itálico nosso)

Com essa visão sobre o objeto de estudo da Ciência da Informação, González de Gómez (2003b) acrescenta à abordagem de Frohmann (1995) a perspectiva das instâncias políticas de intervenção em um dado regime de informação, mediante o desenvolvimento de ações de informação cujos processos e resultados convergem para a informação em si. Assim posto, a autora analisa a informação enquanto ação de informação na perspectiva de que estas constituem um conjunto de estratos heterogêneos e articulados, como resumimos, a seguir. 
O estrato de informação, de modo restrito, "remete a formações discursivas e a comunidades de informação, expressando as heterogeneidades e singularidades dos sujeitos e suas formas de vida". 0 estrato das infra-estruturas, que "remete àquilo que disponibiliza e deixa disponível, como sua mediação sóciocultural, um valor de informação, e que poderíamos caracterizar como ação tecno-econômica" E o estrato meta-informacional, "onde se estipula o domínio relacional ou o contexto dentro do qual algo apresenta ou representa um valor de informação" (GONZÁLEZ DE GÓMEZ, 2003a, p.33-34).

Ademais, conforme González de Gómez (2003a, p.36-37), no espaço de um regime de informação o conjunto dos estratos das ações de informação se articulam e se manifestam através de três modalidades:

a) mediação - quando a informação se desenvolve no âmbito de outra ação social, cujos atores são vistos como sujeitos funcionais;

b) formativa - quando orientada à finalização da informação, cujos atores são vistos como sujeitos experimentadores;

c) relacional - quando busca intervir em outra ação para dela obter direção e finalidade, ampliando seu espaço de realização, cujos atores são sujeitos sociais articuladores.

Nesse contexto, as atividades do LTi podem ser vistas como "ações de informação, as quais remetem aos atores que as agenciam, aos contextos e situações em que acontecem e aos regimes de informação em que se inscrevem", como propõe González de Gómez (2003a, p.33) sobre o campo de interesse da Ciência da Informação. No regime de informação do LTi os atores sociais que planificam e promovem as ações de informação participam de uma mesma forma de vida, uma comunidade acadêmica, a qual pode ser interpretada como um coletivo inteligente, conforme as características propostas por Lévy (2000), no contexto de uma "economia das qualidades humanas", a saber:

- compartilhamento de conhecimentos, "o que é a condição elementar da inteligência coletiva” (LÉVY, 2000, p.18);

- engajamento da identidade pessoal na atividade profissional, numa mobilização individual mas coletiva, ética e cooperativa;

- desenvolvimento de uma engenharia do laço social, vista como "a arte de suscitar coletivos inteligentes e valorizar ao máximo a diversidade das qualidades humanas" (LÉVY, 2000, p.32) em uma comunidade acadêmica.

No contexto do LTi esses fios conceituais se entrelaçam com os fios conceituais das ações de informação no regime de informação através da rede de projetos, que funciona de forma autônoma de acordo com a programação das disciplinas, a disponibilidades dos discentes e o próprio desenvolvimento do projeto, de modo que ações de mediação e ações formativas convergem para as ações relacionais, que transformam os processos e produtos em objetos de reflexão e aprendizagem, cujos resultados são compartilhados na comunidade científica. $\mathrm{Na}$ figura 4, a seguir, representamos a rede de projetos na perspectiva da articulação entre os níveis de atuação da universidade pública na comunidade acadêmica e na sociedade, cujo resultado mais expressivo é a interface do LT $\boldsymbol{i}$ na Internet:8

${ }^{8}$ Disponível em $<\underline{\text { www.lti.pro.br }}>$. 


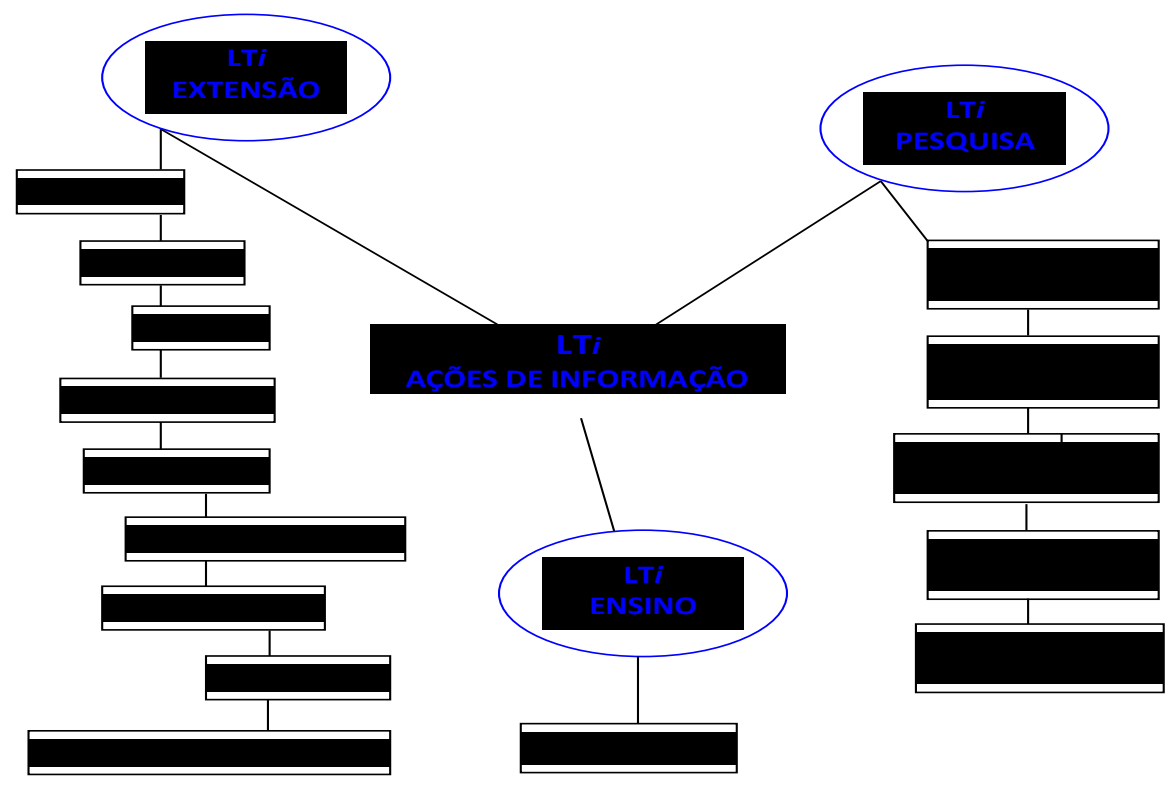

Figura 4: Rede de projetos do LTi ${ }^{9}$ Fonte: FREIRE; FREIRE, 2014.

E na figura 5 representamos os elementos Artefatos (destacando as mídias) e Dispositivos do regime de informação produzidos na rede de projetos do LTi (inclusive escopo da pesquisa), como indícios da emergência de uma inteligência coletiva, os quais podem ser caracterizados como Ações de informação para mediação, formação e reflexão sobre a aplicação do modelo teórico ao regime de informação em uma dada comunidade acadêmica:

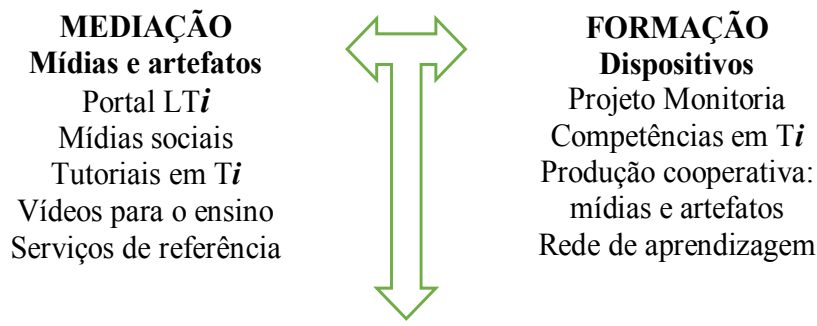

RELACIONAL

Compartilhamento colaborativo

Comunicação científica

Aplicação teórica

Experimentação

Modelos

Figura 5: Articulação entre ações de informação: indícios da inteligência coletiva

Fonte: Elaborado pela autora, 2016.

No escopo da nossa abordagem no Projeto LTi, a teia da rede de projetos e comunicação adquire inestimável valor heurístico, no que concerne ao entendimento da dinâmica das ações de informação, especialmente no que concerne à emergência de uma inteligência coletiva, tanto na perspectiva política, da

${ }^{9}$ O mapa do site descreve os níveis de produtos e serviços compartilhados pela Equipe da pesquisa no Portal LTi

<http://www.lti.pro.br/?\&sitemap>. 
formulação de propostas, quanto para compartilhar e discutir os resultados de ações em curso e planejamentto de novas ações.

\section{ATORES E AÇõES PARA INTELIGÊNCIA COLETIVA}

Nosso campo de pesquisa dos indícios de um projeto de inteligência coletiva em uma comunidade acadêmica, está definido pela vinculação dos participantes do Projeto LTi a atividades de pesquisa, ensino e extensão em curso no Departamento de Ciência da Informação da Universidade Federal da Paraíba.

$\mathrm{Na}$ comunidade acadêmica do LIi, que representa uma especificidade da forma de vida científica geral vigente no espaço do saber, os pesquisadores-autores são definidos por sua atividade de ensino na graduação e pós-graduação, por suas atividades de proposição e coordenação de projetos na rede de projetos do LTi, e pelo compartilhamento dos resultados dos projetos em eventos e periódicos científicos.

Os pesquisadores-colaboradores também são definidos por sua atividade de ensino na graduação e pós-graduação, pela parceria com o LTi mediante compartilhamento de projetos institucionais ou pesquisas individuais, contudo ainda não compartilharam os resultados dessas atividades em eventos e periódicos científicos.

Os pesquisadores-aprendizes são definidos por sua condição de alunos do ensino superior, apoiados ou não por programas institucionais de iniciação científica, que eventualmente compartilham experiências e aprendizado em eventos acadêmicos locais, regionais e nacionais, nas respectivas áreas de formação profissional.

Os atores atuam de forma autônoma, porém cooperativa, criando uma sinergia entre ações desenvolvidas na rede de projetos do LTi. Na figura 6, a seguir, compartilhamos uma representação gráfica dos principais grupos de atores no regime de informação do LTi:

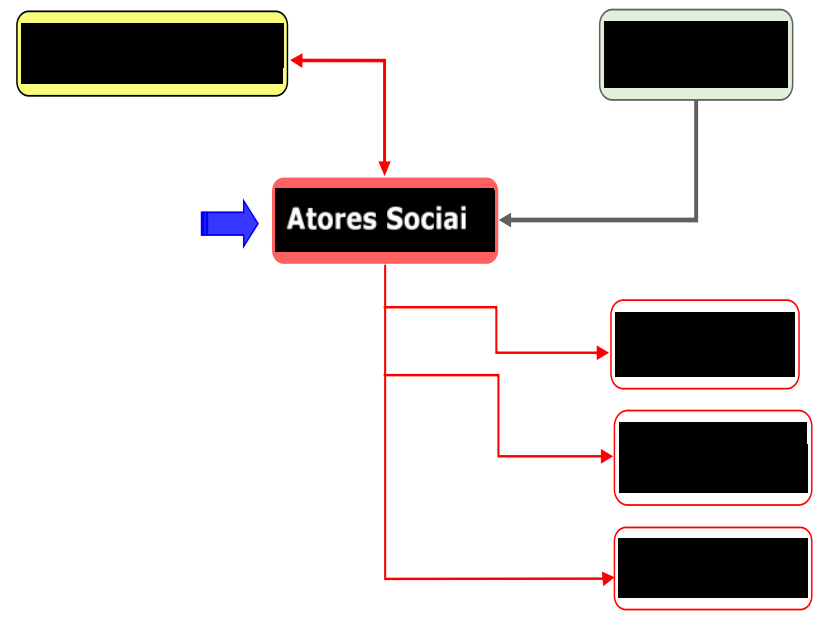

Figura 6: Atores sociais no regime de informação do LTi

Fonte: Elaborado pela autora, 2016.

Com relação à caracterização das ações de informação no LTi, observamos, em relação ao estrato de informação, que se trata de ações direcionadas ao setor científico e tecnológico da produção social, particularmente à comunidade acadêmica e aos profissionais da informação. Nesse sentido, expressam as "heterogeneidades e singularidades das [formas de vida] dos sujeitos", quando buscam atender docentes, discentes, pesquisadores e profissionais atuantes no 
campo da Ciência da Informação, como esclarece González de Gómez (2003a, p.34). No domínio das modalidades, constituem as ações de informação formativas, representada pelas ações cooperativas para compartilhamento de artefatos de informação na interface virtual do Projeto na Internet, as quais estão articuladas com ações de mediação e meta-informacionais em curso no regime de informação do LTi.

Com relação ao estrato relacional, ou meta-informacional, observamos que as ações de informação da rede de projetos do LTi se inserem nos espaços institucionais do Estado (mediante as políticas governamentais de fomento à Ciência e Tecnologia), do campo científico (sendo um projeto de pesquisa), da educação formal (sendo vinculadas a instituição de ensino superior), da legislação (objetos de práticas orientadas por regulamentos) e dos contratos (termos de concessão de recursos públicos). No domínio das modalidades, constituem as ações de informação relacionais representada pelas ações de formação científica e treinamento profissional para uma forma de vida acadêmica, através das quais são criados, cooperativamente, os dispositivos e artefatos de informação disponibilizados no Portal LTi.

Observamos, por fim, que o estrato de infraestruturas de informação, "definido na indústria e nos mercados das tecnologias, das máquinas e dos produtos [...] mediante ações tecno-econômicas, normas técnicas, modelos", conforme González de Gómez (2003a, p.34), diz respeito aos objetos de informação criados pelas atividades colaborativas do LTi, dos quais o sítio virtual é o principal representante. No domínio das modalidades, constituem as ações de mediação para compartilhamento de artefatos de informação na interface virtual do Projeto na Internet, as quais estão atreladas a ações de mediação e meta-informacionais em curso no regime de informação do LTí.

Na figura 7, a seguir, representamos uma tipologia das modalidades das ações de informação em curso no regime de informação do LTi:

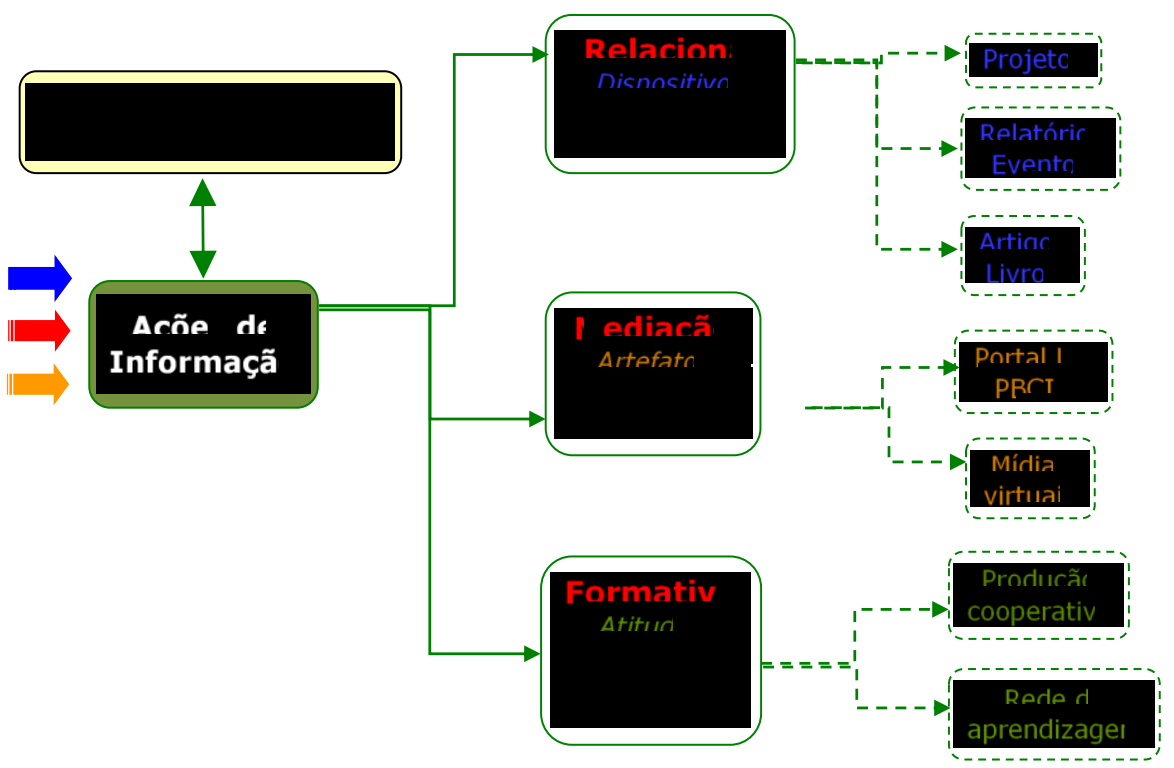

Figura 7: Modalidades das ações de informação no LTi Fonte: Elaborado pela autora, 2016.

Desse modo, é possível dizer que as ações de informação na rede de projetos do regime de informação do LTi se caracterizam como de interesse para o campo da Ciência da Informação, por constituírem uma ação de informação em si, 
produzida e direcionada para uma forma de vida constituída "pelas interações duradouras de um grupo que partilha de atividades, situações e experiências comuns" (GONZÁLEZ DE GÓMEZ (2003a, p.36), definido como "comunidade acadêmica"; bem como uma ação para infraestrutura de informação, representada pela interface virtual na rede internet, que se propõe facilitar a comunicação da informação produzida cooperativamente pelos atores sociais; e uma ação de metainformação, por se constituir também em objeto de pesquisa teórica, ademais de seus aspectos de pesquisa aplicada, representando oportunidade para reflexão sobre as ações de informação em um dado regime de informação, na perspectiva da emergência da inteligência coletiva.

Pois a articulação entre as ações de informação, favorecida pelo modelo de rede de projetos aplicado ao LTi, representam, a nosso ver, os mais fortes indícios de uma inteligência coletiva no regime de informação do LTi, atuando cooperativamente para promover o acesso à informação, na área de Ciência da Informação, na Internet. Trata-se do modelo de rede conceitual aplicado a um regime de informação onde as ações de mediação, formativas e relacionais atuam e se entrelaçam com os fios conceituais das tecnologias intelectuais, mobilizadas mediante pesquisa-ação, para promover competências em informação e propiciar a emergência de um projeto de inteligência coletiva na comunidade acadêmica que participa do Laboratório de Tecnologias Intelectuais.

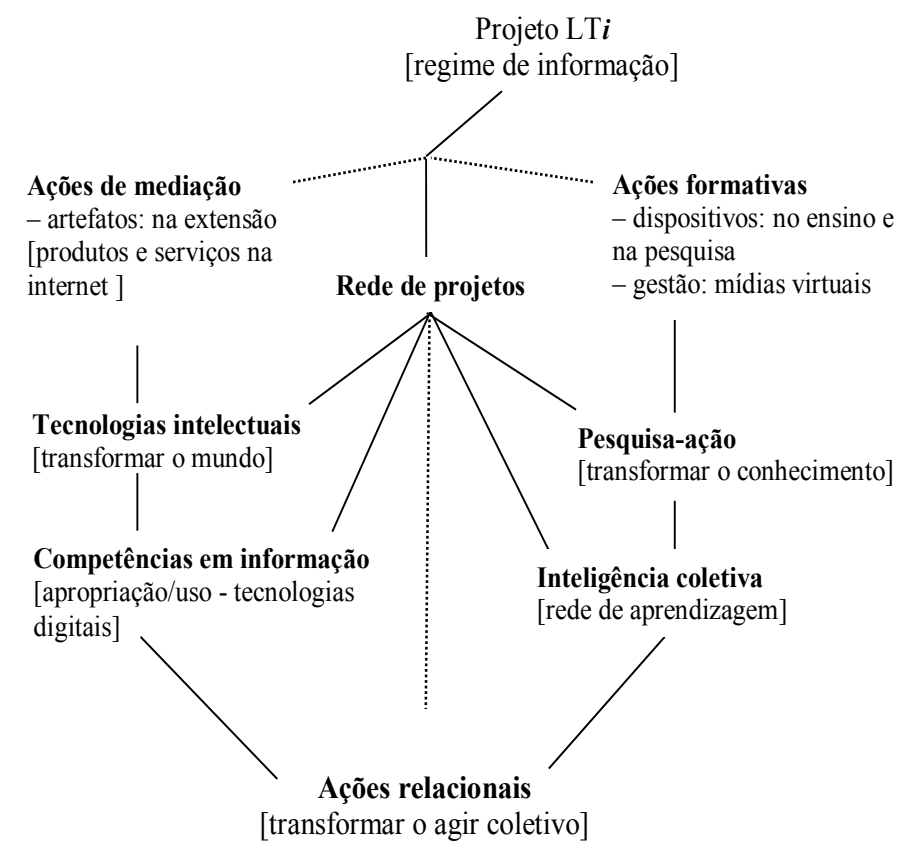

Figura 8: Rede conceitual do regime de informação do LTi

Fonte: Elaborado pela autora, 2017.

Nesse contexto, a aplicação do modelo de rede de projetos na gestão das ações de informação, em um dado regime de informação, tem contribuído para promover a produção e comunicação cooperativas da informação, bem como para apropriação de competências em informação pelos atores que participam de uma dada forma de vida, no caso a comunidade acadêmica de Ciência da Informação da UFPB. Destarte, a forma de vida acadêmica tradicionalmente trabalha no contexto da economia das qualidades humanas, aplicando critérios de mérito para seleção dos participantes e estabelecendo laços sociais estáveis através da vinculação de docentes e discentes a cursos de graduação e pós-graduação.

A experiência está indicando que a partir desse modelo cresceram as oportunidades de apropriação, pelos atores envolvidos, de tecnologias intelectuais 
digitais para produção e compartilhamento de informações no ciberespaço. Essas oportunidades têm sido identificadas, apropriadas e utilizadas pelos docentes no regime de informação do LTi para elaboração de novos projetos de produção e compartilhamento cooperativos de informações de interesse para a área de Ciência da Informação, integrando ações de política e gestão da informação em um mesmo contexto, contribuindo para facilitar a transmissão do conhecimento para aqueles que dele necessitam.

\section{CONSIDERAÇÕES SOBRE O PROCESSO}

Com este modelo de abordagem, corroboramos González de Gómez quando diz que é possível encontrar, no campo da Ciência da Informação, recursos teóricos e tecnológicos que promovam a socialização da informação, mediante apropriação e uso de tecnologias intelectuais de informação. E, também, quando destaca que essa abordagem singulariza a Ciência da Informação no campo das ciências que adotam a informação como objeto de estudo, e a coloca "numa posição preferencial para fortalecer o olhar comunicacional e gnosiológico em processos e domínios que até agora têm sido explicitados à luz de fatores econômicos ou tecnológicos" (2003a, p.38).

Pudemos observar, no regime de informação da forma de vida do campo da Ciência da Informação no Brasil, onde se articulam os estratos, domínios e modalidades das ações polimórficas e mimeomórficas, no âmbito de ações formativas e de mediação inerentes ao campo acadêmico, o desenvolvimento de ações para infraestrutura de informação representadas por

(i) interfaces virtuais dos produtos e serviços de informação produzidos cooperativamente pela rede de projetos do LTi;

(ii) interfaces virtuais de produtos e serviços de informação produzidos por parceiros e disponibilizados no Portal LTi;

(iii) mídias sociais virtuais para comunicação da informação, no âmbito do Projeto de Responsabilidade Social do Campo Científico da Informação na Sociedade em Rede.

Bem como ações de meta-informação, uma vez que a dinâmica criada pelos atores e suas ações, no âmbito de um dado regime de informação, conforme figura 4 , também se constitui em objeto de pesquisa teórica ou epistemológica no campo da Ciência da Informação, ademais de seus aspectos de pesquisa aplicada, representando oportunidade para reflexão sobre problemas de informação. Nesse sentido, o processo de reflexão teórica sobre a experiência com o Projeto LTi continuará a ocupar um espaço em nossos estudos sobre o regime de informação em uma dada forma de vida - a comunidade científica - valorizada na sociedade contemporânea, caracterizada como espaço do saber.

Mas nosso propósito não é somente refletir, mas, especialmente, contribuir para a formulação e discussão de modelos de intervenção no ciberespaço, de modo a criar oportunidades para acesso, apropriação e uso das tecnologias intelectuais digitais de comunicação e informação, valorizando o campo da Ciência da Informação na sociedade contemporânea.

\section{REFERÊNCIAS}

DELAIA, C.R. Subsídios para uma política de gestão da informação na EMBRAPA

Solos. 2008. Dissertação (Mest. Ci. da Inf.). Niterói: IBICT - UFF, 2008. 
FREIRE, I.M. Indícios da inteligência coletiva no regime de informação do Laboratório de Tecnologias Intelectuais - LTi. In: Encontro Nacional de Pesquisa em Ciência da Informação, 2016, Salvador, BA. XVII ENANCIB. Anais. Salvador: UFBA, 2016. v.1. p.1-20.

FREIRE, I.M. Breve reflexão sobre as ações de informação no Laboratório de Tecnologias Intelectuais - LTi. Revista do Mestrado Profissional Gestão em Organizações Aprendentes, v. 4, n.1, p. 45-58, 2015.

FREIRE, I.M. Tecendo uma rede conceitual na Ciência da Informação: tecnologias intelectuais para competências em informação. Informação \&Tecnologia, v.1, n.1, 2014.

FREIRE, I.M. Sobre o regime de informação no Laboratório de Tecnologias Intelectuais - LTi. InCID: Revista de Ciência da Informação e Documentação, v.4, n.1, p. 70-86, jan./jun. 2013.

FREIRE, I.M. Categorização das ações de informação no Laboratório de Tecnologias Intelectuais - LTi. Tendências da Pesq. Brasil. em Ciência da Informação, v.5, n.1, [s.p.], 2012.

FREIRE, I.M. A rede de projetos do núcleo temático da seca da UFRN como possibilidade de socialização da informação. Informação \& Sociedade: Estudos, v.14, n.2, p. 201-216, 2004.

FREIRE, I.M. A responsabilidade social da ciência da informação e/ou 0 olhar da consciência possível sobre o campo científico. 2001. Tese (Dout. Ciência da Informação). Rio de Janeiro: IBICT - UFRJ, 2001.

FREIRE, I.M.; FREIRE, G.H. de A. Ações para produção e compartilhamento de informação no Laboratório de Tecnologias Intelectuais - LTi. In: GARCIA, J.C.R.; TARGIBO, M. das G.

Desvendando facetas da gestão e políticas de informação. João Pessoa: Editora UFPB, 2015.

FROHMANN, Bernd. Taking information policy beyond information science: applying actor network theory. In: ANNUAL CONFERENCE OF THE CANADIAN ASSOCIATION FOR INFORMATION SCIENCE, 23., 1995. Edmonton. Electronic proceddings... 14p. Disponível em: http://www.cais-acsi.ca/1995proceedings.htm. Acesso em: 10/5/2005.

GONZÁLEZ DE GÓMEZ, M.N. As relações entre ciência, Estado e sociedade: um domínio de visibilidade para as questões da informação. Ciência da Informação, v.32, n. 1, p. 60-76, 2003b.

GONZÁLEZ DE GÓMEZ, M.N. Escopo e abrangência da Ciência da Informação e a PósGraduação na área: anotações para uma reflexão. Transinformação, v.15, n.1, p.31-43, 2003a.

GONZÁLEZ DE GÓMEZ, M.N. Novos cenários políticos para a informação. Ciência da Informação, v.31, n. 1, p. 27-40, 2002.

GONZÁLEZ DE GÓMEZ, M.N. Da política de informação ao papel da informação na política contemporânea. Revista Internacional de Estudos Políticos, v.1, n.1, p.57-93, 1999.

LÉVY, P. Filosofia world: O Mercado; O Ciberespaço: A Consciência. Lisboa: Inst. Piaget, 2001.

LÉVY, P. A inteligência coletiva: por uma antropologia do ciberespaço. SP: Loyola, 2000.

LÉVY, P. Cibercultura. São Paulo: Ed. 34, 1999.

UNGER, R.J.G.; FREIRE, I.M. Regimes de informação na sociedade da informação: uma contribuição para a gestão da informação. Revista Digital de Biblioteconomia e Ciência da Informação, n.2. 2008.

WERSIG, G. Information science: the study of postmodern knowledge usage. Information Processing \& Management, v.29, n.2, 1993. 